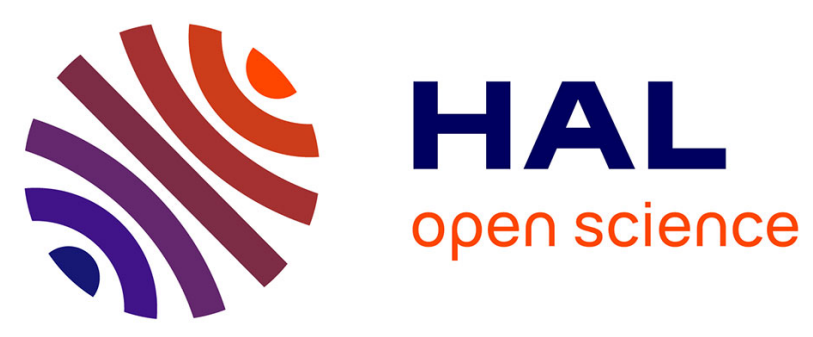

\title{
Deep winds beneath Saturn's upper clouds from a seasonal long-lived planetary-scale storm
}

\author{
A. Sánchez-Lavega, T. del Río-Gaztelurrutia, R. Hueso, J. M. \\ Gómez-Forrellad, J. F. Sanz-Requena, J. Legarreta, E. García-Melendo, \\ François Colas, Jean Lecacheux, L. N. Fletcher, et al.
}

\section{To cite this version:}

A. Sánchez-Lavega, T. del Río-Gaztelurrutia, R. Hueso, J. M. Gómez-Forrellad, J. F. Sanz-Requena, et al.. Deep winds beneath Saturn's upper clouds from a seasonal long-lived planetary-scale storm. Nature, 2011, 475 (7354), pp.71-74. 10.1038/NATURE10203 . hal-00639431

\section{HAL Id: hal-00639431 \\ https://hal.sorbonne-universite.fr/hal-00639431}

Submitted on 6 Nov 2012

HAL is a multi-disciplinary open access archive for the deposit and dissemination of scientific research documents, whether they are published or not. The documents may come from teaching and research institutions in France or abroad, or from public or private research centers.
L'archive ouverte pluridisciplinaire HAL, est destinée au dépôt et à la diffusion de documents scientifiques de niveau recherche, publiés ou non, émanant des établissements d'enseignement et de recherche français ou étrangers, des laboratoires publics ou privés. 


\section{Deep winds beneath Saturn's upper clouds from a seasonal long-lived planetary- scale storm}

A. Sánchez-Lavega ${ }^{1}$, T. del Río-Gaztelurrutia ${ }^{1}$, R. Hueso ${ }^{1}$, J. M. Gómez-Forrellad ${ }^{2}$, J. F. Sanz-Requena $^{3}$, J. Legarreta ${ }^{4}$, E. García-Melendo ${ }^{2,5}$, F. Colas ${ }^{6}$, J. Lecacheux ${ }^{7}$, L. N. Fletcher $^{8}$, D. Barrado-Navascués ${ }^{9}$, D. Parker ${ }^{10} \&$ the International Outer Planet Watch Team IOPW-PVOL*

${ }^{1}$ Departamento de Física Aplicada I, E.T.S. Ingenieros, Universidad del País Vasco, Alameda Urquijo s/n, 48013 Bilbao (Spain).

${ }^{2}$ Esteve Duran Observatory Foundation, Seva (Spain).

${ }^{3}$ Universidad Europea Miguel de Cervantes, Valladolid (Spain)

${ }^{4}$ Departamento de Ingeniería de Sistemas y Automática, E.U.I.T.I., Universidad País Vasco, Bilbao (Spain).

${ }^{5}$ Institut de Ciències de lEspai (CSIC-IEEC), Campus UAB, Facultat de Ciències, Torre C5, parell, 2 a pl., E-08193 Bellaterra, Spain.

${ }^{6}$ Institut de Mécanique Céleste et de Calcul des Ephémérides, Bureau des Longitudes, Paris (France)

${ }^{7}$ LESIA, Observatoire de Paris-Meudon, Paris (France)

${ }^{8}$ Atmospheric, Oceanic and Planetary Physics, Department of Physics, Clarendon Laboratory, University of Oxford, Parks Road, Oxford, OX1 3PU (UK).

${ }^{9}$ Centro Astronómico Hispano Alemán, Observatorio de Calar Alto MPIA-CSIC, Almería (Spain) 
${ }^{10}$ Association of Lunar and Planetary Observers (ALPO), Coral Gables, Florida (USA)

* A list of participants of the International Outer Planet Watch Team IOPW-PVOL appears at the end of the paper.

Mailing address:

Prof. Agustín Sánchez-Lavega

Departamento Física Aplicada I

Escuela Técnica Superior de Ingeniería

Alda. Urquijo s/n

48013 BILBAO (SPAIN)

Telephone: (34)-94.601.42.94

Fax: (34)-94.601.41.78

e-mail: agustin.sanchez@ehu.es 
Convective storms occur regularly in Saturn $\sqrt{\text { S }}$ atmosphere ${ }^{1-4}$. Huge storms known as Great White Spots (GWS), which are ten times larger, are more rare and occur once per Saturn year (29.5 Earth years) ${ }^{5-8}$. Current models propose that the GWS outbreak is due to water moist convection ${ }^{9,10}$ but the generation of the global disturbance and its effect on Saturn $s$ permanent winds ${ }^{1,11}$ has hitherto remained unconstrained $^{12}$ by data, because there was insufficient spatial resolution and temporal sampling ${ }^{6-8}$ to infer the dynamics of Saturn $\sqrt{s}$ weather layer. Theoretically, it had been suggested that this phenomenon is seasonally controlled ${ }^{6-}$ ${ }^{7,9}$. Here we report observations of a storm at northern latitudes in the peak of a weak westward jet during early northern springtime, as expected. The storm head moved faster than the jet, was active during the two months reported observation period and triggered a planetary scale disturbance that circled Saturn and did not significantly alter the ambient zonal winds. Numerical simulations of the phenomenon show that, like in Jupiter ${ }^{13}$, Saturn $\checkmark$ winds extend without decay deep down into the weather layer, at least to the water cloud base at $10 \square 12$ bar, much deeper than solar radiation penetrates. 
Ground-based telescopes detected the first signs of the storm in December $5^{\text {th }} 2010$ at Universal Time (UT) $21 \mathrm{hr} 05 \mathrm{~min} 22 \mathrm{~s}$ when a barely visible bright point emerged at planetographic latitude $37.7 \pm 0.8^{\circ}$ North (Figure 1 ). This is nearly simultaneous with detection of electric activity linked to the storm at $19 \mathrm{hr} 18 \mathrm{~min}$ UT from the Radio Plasma Wave Science (RPWS) instrument onboard the Cassini spacecraft ${ }^{14}$ when considering the 80 minutes light travel time from Saturn to Earth at this epoch. As in previous GWS eruptions ${ }^{5-6,9,15}$ the spot grew rapidly both in size and brightness, expanding from a length of $\sim 3,000 \mathrm{~km}$ to $8,000 \mathrm{~km}$ in just one week. The head of the storm centered at latitude $41.1 \pm 1.1^{\circ} \mathrm{N}$ had a rotation period about Saturn of $10 \mathrm{hr} 41$ min $43.6 \mathrm{~s}$, implying a westward zonal wind speed of $-28.7 \pm 0.2 \mathrm{~ms}^{-1}$ in System III reference frame ${ }^{16}$. Two weeks after the outbreak, the GWS consisted of a bright compact spot ( the storm head $\square$ ) followed eastward by a zonally expanding tail of bright clouds between latitudes $30^{\circ} \mathrm{N}$ and $45^{\circ} \mathrm{N}$ (Figure 2). This tail formed a planetary-scale disturbance that encircled the planet in 55 days. The shape of the head of the storm and its drift rate remained unperturbed following the encounter, a behavior consistent with the drag of the disturbance clouds by ambient zonal winds, in a similar way as observed in the last GWS event in the Equator in $1990^{6-8,15}$.

Tracking of individual cloud elements (sizes $\sim 1000-3000 \mathrm{~km}$ ) during the observing period (December $5^{\text {th }} 2010 \square$ February $19^{\text {th }} 2011$ ) allowed us to derive their motions (Figure 3, see also S.I.). The drift rate of the head of the storm did not change in this period, with the storm head moving westwards $10 \mathrm{~ms}^{-1}$ faster than the westward-jet peak velocity. On the other hand, disturbance features moved in the zonal direction with speeds very close to the ambient winds. Therefore winds at the upper cloud level, which 
have remained essentially unchanged throughout a whole Saturn year ${ }^{1,11}$, were not altered by the disturbance at this early stage.

Observations obtained with a variety of filters from the ultraviolet $(375 \mathrm{~nm})$ to the near infrared $(954 \mathrm{~nm})$ including the deep methane absorption band at $883 \mathrm{~nm}$, showed that the GWS is brighter relative to the adjacent undisturbed area at the same latitude by $10 \%(375 \mathrm{~nm}), 19 \%(450 \mathrm{~nm}), 25 \%(537 \mathrm{~nm}), 16 \%(580 \mathrm{~nm})$ and $11 \%(630 \mathrm{~nm})$. At $375 \mathrm{~nm}$ Rayleigh scattering contributes to the brightness but at the other wavelengths free of the gaseous methane absorption, brightness is essentially controlled by the storm particles $^{17}$, suggesting that the storm injects fresh ice particles into the tropopause, where they mix with the pre-existing haze. In order to retrieve the vertical cloud structure of the storm we used a standard three-layer radiative transfer model for Saturn ${ }^{18-20}$. The model atmosphere consisted of a stratospheric haze of thin Mie particles of size $\sim 0.1 \mu \mathrm{m}$ located between 2 and $60 \mathrm{mbar}$, and a dense tropospheric haze extending from 0.1 bar down to the ammonia cloud deck at 1.4 bar. We found that the GWS was embedded within the tropospheric haze, with its cloud tops located at $\sim 150$ mbar, that is, $3 \mathrm{~km}$ below the top of the haze, and $20 \mathrm{~km}$ below the tropopause, located near 100 mbar according to thermal infrared measurements ${ }^{21}$.

The rapid growth and high brightness of the GWS core, together with the abundant electric activity detected by Cassini RWPS instrument ${ }^{14}$, are consistent with previous proposals that these events are moist convective storms driven by ammonia and water condensation (at the 1-2 bar and 10-12 bar level respectively) ${ }^{9,10}$. Flow divergence at the top of the ascending motions can be related to the growing area $A$ of the storm (Figure 1) through mass continuity by $\operatorname{div} V=(1 / A)(d A / d t)=1-5 \times 10^{-6} \mathrm{~s}^{-1}$ (where $V$ is 
the horizontal velocity). This implies a vertical velocity at the cloud top of the storm $w \leq h \cdot \operatorname{div} V \cong 2.5 \mathrm{~ms}^{-1}$, where $h=260 \mathrm{~km}$ is the vertical length of the path followed by the ascending convective parcels from altitude levels $P_{\text {bottom }} \sim 10$ bar (water clouds) to $P_{\text {top }} \sim 0.1$ bar (the tropopause). However, deep moist convection in Saturn is vigorous in the core of the ascending convective towers ${ }^{9,10}$ and to first order the maximum vertical velocity $w_{\max }$ can be related to the Convective Available Potential Energy (CAPE) by $\mathrm{CAPE}=\int_{z_{1}}^{z_{2}} g \frac{\Delta T}{T(z)} d z=\frac{w_{\max }^{2}}{2}$, where $g$ is the acceleration of gravity and $\Delta T$ is the temperature difference between the ascending parcel and the ambient with vertical temperature profile $T(z)$. Assuming a constant $\Delta T$ of just $1 \mathrm{~K}$, this results in $w_{\max }=\sqrt{2 \mathrm{CAPE}} \sim\left(2 g \frac{\Delta T}{<T>} h\right)^{1 / 2} \sim 150 \mathrm{~ms}^{-1}$ for $g=10 \mathrm{~ms}^{-1}$ and mean temeprature $<T>=250 \mathrm{~K}$. Given the high vertical velocities, large vertical extent of the GWS core, and its enormous horizontal size, of the order of the width of the mid-latitude jets, this huge disturbance serves as a tool to diagnose the dynamics of Saturn $\sqrt{s}$ weather layer from the 10 bar deep troposphere to 0.01 bar or higher in the stratosphere.

In order to explain the disturbance structure at cloud level, we ran nonlinear simulations of the response of Saturn $\varangle$ upper troposphere and stratosphere to a steady vertical heat source that tries to mimic the GWS convective storm head using the EPIC $\operatorname{code}^{22,22}$. We tested the structure of the atmosphere varying the zonal wind vertical profile and thermal structure in a forward modeling of the potential vorticity $(P V)$ field ${ }^{23}$. Since both $P V$ and cloud field are considered to act as passive tracers of the flow, we sought the $P V$ field evolution that best reproduced the observed cloud morphology. Figure 4 shows results from a simulation of the first 12 days of the $P V$-field that highly 
resembles the cloud disturbance evolution (compare to Figures 2a-c and Figure 3 in ref. 14). These successful simulations require a weather layer with a very low static stability $N=0.0017 \mathrm{~s}^{-1}$, close to a neutral profile, and winds that increase slightly with depth across it (from 0.5 to 10 bar). In addition the wind structure changes very little as the disturbance progressed in agreement with what we observe at cloud level.

GWSs have been observed to occur one per Saturn year in the northern hemisphere summertime season ${ }^{6-7,9}$. The 2010 event occurred at a much earlier springtime season within the same westward jet as the 1903 event $^{5-9}$, ponting towards seasonal insolation as their triggering mechanism. This is puzzling since the solar radiation penetration in Saturn $\triangle$ atmosphere ${ }^{24}$ and thermal infrared measurements ${ }^{21,25}$, indicate that seasonal temperature changes occur only above $\sim 500$ mbar altitude, much higher than the 10-12 bar level for the storm source ${ }^{9-10}$. The zonal wind profile at $0.5 \square 1$ bar level does not change over one Saturn year ${ }^{1,11}$ (Figure 3) ruling out a related seasonal dynamical instability,. The deep trigger could then be induced by seasonal changes in the upper troposphere temperature gradients affecting directly the deep vertical motions or indirectly modifying the pattern of meridional cell circulations between opposed jets proposed to exist at different altitudes in the weather layer ${ }^{1,26}$.

The observed GWS properties and its modeling suggests that a reservoir of water vapor must exists at the 10-12 bar level in the westward jet with sustained strong convergence to fuel the storm ${ }^{9,10}$. The GWS extend vertically $\sim 260 \mathrm{~km}$ below cloud tops across the weather layer ( $0.5 \square 10$ bar) where zonal winds keep constant or slightly increasing with depth in agreement with both previous observations and models of mid-latitude Saturn $\operatorname{vortices}^{27-28}$ and wind speed measurements at 2-3 bar level ${ }^{29}$. The huge planetary scale 
disturbance triggered by the GWS did not modify substantially the westward zonal jet structure indicating that Saturn tropospheric winds are robust and extend well below the sunlight penetration level, altogether favoring the hypothesis for their deep origin ${ }^{1}$ as also found for Jupiter $\triangle$ s winds ${ }^{13}$. 


\section{References}

1. Del Genio A. D. et al. Saturn Atmospheric Structure and Dynamics in Saturn after

Cassini-Huygens. M. Dougherty, L. Esposito and T. Krimigis (edt.), Springer-Verlag, pp. 113-159 (2009).

2. Porco, C.C. et al. Cassini Imaging Science: Initial Results on Saturn $₫$ Atmosphere. Science 307, 1243-1247 (2005).

3. Dyudina U. A. et al. Lightning storms on Saturn observed by Cassini ISS and RPWS during 2004-2006. Icarus, 190, 545 - 555 (2007)

4. Fischer G. et al. Analysis of a giant lightning storm on Saturn. Icarus, 190, 528-544 (2007).

5. Sánchez-Lavega, A. Motions in Saturn $\$$ s Atmosphere: Observations before Voyager Encounters. Icarus, 49, 1 - 16 (1982).

6. Sánchez-Lavega, A. et al. The Great White Spot and disturbances in Saturn $\$$ equatorial atmosphere during 1990. Nature, 353, 397 - 401 (1991).

7. Sánchez-Lavega A., Lecacheux J., Colas F., Laques P. Temporal behavior of cloud morphologies and motions in Saturn $₫$ atmosphere. J. Geophys. Res., 98 (E10), 18857 $18872(1993)$. 
8. Barnet C. D., Westphal J. A., Beebe R. F., Huber L. F. Hubble Space Telescope Observations of the 1990 Equatorial Disturbance on Saturn: Zonal Winds and Central Meridian Albedos. Icarus, , 100, 499-511 (1992).

9. Sánchez-Lavega A., Battaner E. The Nature of Saturn $\$ s atmospheric Great White Spots. Astron. Astrophys., 185, 315-326 (1987).

10. Hueso, R., Sánchez-Lavega A. A Three-Dimensional Model of Moist Convection for the Giant Planets II: Saturn's water and ammonia moist convective storms. Icarus, 172, 255-271 (2004).

11. Sánchez-Lavega A., Rojas J.F., Sada P.V. Saturn $₫$ zonal winds at cloud level. Icarus, 147, 405-420 (2000).

12. Sayanagi K. M., Showman A. P., Effects of a large convective storm on Saturn $₫$ equatorial jet, Icarus, 187, 520-539 (2007).

13. Sánchez-Lavega A. et al. Depth of a strong jovian jet from a planetary-scale disturbance driven by storms. Nature, 451, 437- 440 (2008).

14. Fischer, G. et al. Seasonal variation of giant thunderstorms on Saturn, Nature, this issue (2011). 
15. Beebe, R. F., Barnet C., Sada P. V., Murrell A. S. The Onset and Growth of the 1990 Equatorial Disturbance on Saturn. Icarus, 95, $163 \square 172$ (1992).

16. Seidelmann, P. K., et al. Report of the IAU/IAG working group on cartographic coordinates and rotational elements: 2006. Celestial Mech. Dyn. Astr. 98, $155 \square 80$. (2007).

17. Sánchez Lavega A. et al. Large-scale storms in Saturn『s atmosphere during 1994. Science, 271, 631 - 634 (1996).

18. Acarreta, J.R., Sánchez-Lavega A. Vertical cloud structure in Saturn $\$ 1990$ equatorial storm. Icarus, 137, 24『33 (1999).

19. Pérez-Hoyos, S., Sánchez-Lavega, A., French, R.G., Rojas, J.F. Saturn $\$ cloud structure and temporal evolution from ten years of Hubble Space Telescope Images

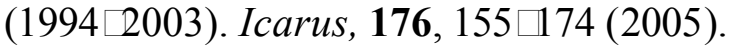

20. West R. A., Baines K. H., Karkoschka E., Sánchez-Lavega A. Clouds and Aerosols in Saturn $₫$ Atmosphere in Saturn after Cassini-Huygens. M. Dougherty, L. Esposito and T. Krimigis (edt.), Springer-Verlag, pp. 161-179 (2009).

21. Fletcher L. N. et al. Seasonal change on Saturn from Cassini CIRS observations, 2004-2009. Icarus, 208, 337-352 (2010) 
22. Dowling, T. E. The Explicit Planetary Insentropic-Coordinate (EPIC) Atmospheric Model. Icarus 132, 221-238 (1998).

23. Read P. L. et al. Mapping potential vorticity dynamics on Saturn: Zonal mean circulation from Cassini and Voyager data, Plan. Space Sci., 57, 1682-1698 (2009).

24. Pérez-Hoyos S., Sánchez-Lavega A. Solar flux in Saturn's atmosphere: maximum penetration and heating rates in the aerosol and cloud layers. Icarus, 180, 368-378 (2006).

25. Li, L. et al. Saturn $\$ emitted power. J. Geophys. Res. 115, E11002 (2010).

26. Barnet C. D., Beebe R. F., Conrath B. J. A seasonal radiative-dynamic model of Saturn $₫$ troposphere. Icarus, 98, 94-107 (1992).

27. García-Melendo E., Sánchez-Lavega A., Hueso R. Numerical models of Saturn $\$$ long-lived anticyclones. Icarus, 191, 665-677 (2007).

28. del Río-Gaztelurrutia T., Legarreta J., Hueso R., Pérez-Hoyos S., Sánchez-Lavega A. A long-lived cyclone in Saturn $\varangle$ atmosphere: observations and models. Icarus, 209, 665-681 (2010).

29. Choi, D. S., Showman A. P., Brown R. H. Cloud features and zonal wind measurements of Saturn's atmosphere as observed by Cassini/VIMS. J. Geophys. Res., 114, E04007, (2009). 
30. Hueso R. et al. The International Outer Planets Watch Atmospheres Node database of Giant Planets images. Planet. Space Sci., 58, 1152-1159 (2010).

\section{Acknowledgements}

ASL, TdRG, RH, JL, JMG, EGM and FSR are supported by the Spanish MICIIN with FEDER and by Gobierno Vasco. We acknowledge S. Pérez-Hoyos for initial support on this study and M. Alises and A. Guijarro from Calar Alto Observatory (CAHA and MPG/CSIC) for the images. EGM used computing facilities at CESCA (Barcelona) supported by MICIIN. LNF is supported by a Glasstone fellowship at the University of Oxford.

\section{Author contributions}

A. Sánchez-Lavega coordinated the study and performed the motion and wind measurements and the interpretation. T. del Río-Gaztelurrutia performed the photometric measurements and filter calibrations. R. Hueso measured the storm growth rate and with J. Legarreta coordinated the IOPW database. J. M. Gómez-Forrellad prepared the maps projections and image search. J. F. Sanz-Requena performed the radiative transfer calculations. E. García-Melendo and J. Legarreta performed the EPIC simulations. F. Colas and J. Lecacheux provided the Pic-du-Midi photometric images. L. N. Fletcher provided data on the thermal structure of the storm. D. BarradoNavascués provided the photometric images obtained at Calar Alto Obs., and D. Parker 
provided photometric images at selected wavelengths. All these authors discussed the results and commented on the manuscript. The International Outer Planet Watch Team IOPW-PVOL and other individual contributors listed in S.I. provided most of the images used for tracking in this study.

(*) Contributors to the IOPW-PVOL database for this study:

T. Akutsu (Cebu, Philippines), T. Barry (Broken Hill, Australia), J Beltran (Castellon, Spain), S. Buda (Melbourne, Australia), B. Combs (Buena Vista GA, USA), F. Carvalho (Assis, Brasil), P. Casquinha (Palmela, Portugal), M. Delcroix (Toumefeuille, France), S. Ghomizadeh (Tehran, Iran ), Christopher Go (Cebu, Philippines), J. Hotershall (Cleveland, Australia), T. Ikemura (Nagoya Aichi, Japan), G. Jolly (USA), A. Kazemoto (Kyoto, Japan), T. Kumamori (Osaka, Japan), M. Lecompte (West London, UK), P. Maxson (Arizona, USA), F. J. Melillo (Holtsville, N.Y., USA), D. P. Milika (USA Sellicks Beach, Australia), E. Morales (Puerto Rico, USA), D. Parker (Florida, USA), D. Peach (Loudwater,Buckinghamshire, UK), J. Phillips (South Carolina, USA), J. J. Poupeau (Pecqueuse, France), J. Sussenbach (Houten, Netherlands), G. Walker (Macon, GA, USA), T. Tranter (Kurri, Australia), A. Wesley (Murrumbateman, Australia), T. Wilson (Woodstock, GA, USA), K. Yunoki (Osaka, Japan). This list was complemented in some cases with images taken from contributors to the ALPO Japan (Association of Lunar and Planetary Observers) database (http://alpo-j.asahikawa-med.ac.jp/indexE.htm)

Correspondence and requests for materials should be addressed to: agustin.sanchez@ehu.es 


\section{Figure Legends}

Figure 1. Initial growth of the Saturn $s$ Great White Spot. Map projected images of the storm clouds obtained in December 5 ( $a$, T. Ikemura), 8 (b, S. Ghomizadeh), 9 ( $c$, T. Kumamori) and 13 ( $d$, C. Go). Measurement of the area occupied by the bright core (without considering the southern tail in the later images) is shown on (e). During the first 13 days after onset the growth rate was $d A / d t=20 \mathrm{~km}^{2} \mathrm{~s}^{-1}$ and then it suffered a second fast expansion during the next two days at a rate of $d A / d t=212 \mathrm{~km}^{2} \mathrm{~s}^{-1}$. The images used in this study were obtained in the visible range (wavelengths $350 \mathrm{~nm} \square 954$ $\mathrm{nm}$ ) by a large number of observers contributing to the IOPW-PVOL database ${ }^{30}$ and the ALPO-Japan database (details are given in the Supplementary Information). Multispectral photometric images were obtained at the 1-m telescope at Pic-du-Midi Observatory (France), the $2.2 \mathrm{~m}$ telescope at Calar Alto Observatory (Spain), and a 0.41 $\mathrm{m}$ telescope (D. Parker). Error bars are r.m.s from several measurements of the storm area over the same image.

Figure 2. Expansion of the storm clouds and planetary-scale disturbance. Maps were made by assembling images from different observers (see Supplementary Information). The storm head moved westward (left in the maps) and showed a bow shape consistent with the meridional zonal wind profile. The bright clouds forming the southern branch of the disturbance (between latitudes $38^{\circ}$ and $30^{\circ} \mathrm{N}$, in a region of cyclonic vorticity) progressed eastward (2a-c). Later on 22 December, a northern branch developed (latitudes $40^{\circ}$ to $45^{\circ} \mathrm{N}$, anticyclonic vorticity) also progressing eastward (2de). In about two months the disturbance encircled the planet, and the southern branch elements, moving in the opposite direction, encountered the head of the storm on the 
$29^{\text {th }}$ of January, $4^{\mathrm{o}}$ southward in latitude (2f). The eastward expansion in longitude of the disturbance central branch (between latitudes $40^{\circ}-42^{\circ}$ ) formed dark spots, one of which was persistent, probably an anticyclonic vortex at latitude $41.9^{\circ} \pm 1.3^{\circ}$ (s.d.) with a size $\sim 4,000 \mathrm{~km}$ (System III Longitude $=308^{\circ}$ in $2 \mathrm{e}$ ). Small bright spots in the southern part of the disturbance at latitudes $+35^{\circ}$ to $+38^{\circ}$ showed a periodic distribution with a dominant zonal wavelength of $15.7^{\circ} \pm 3^{\circ}(2 b-2 f)$ and survived a maximum of approximately two weeks.

Figure 3. Zonal winds from motions of the disturbance clouds. Points correspond to wind speed measured for single tracers pertaining to the disturbance (see SI). The storm head corresponds to the point with the highest westward velocity $\left(-28.7 \mathrm{~ms}^{-1}\right)$. The lines represent wind profiles obtained during the Voyagers encounters in 1980-81 (long dashed, ref. 11) and in 2004-2009 using Cassini images at two altitude levels within the tropospheric haze (solid line) and upper cloud (dashed line). The latitude uncertainty for the points is $\pm 1.3^{\circ}$ (s.d.) and the wind speed uncertainty is $\pm 0.2 \mathrm{~ms}^{-1}$ (s.d.) for the storm head, and ranges from \pm 0.5 to $\pm 2 \mathrm{~ms}^{-1}$ (s.d.) for other features.

Figure 4. Models of the GWS planetary-scale disturbance. Nonlinear EPIC simulations $^{22}$ of the onset and initial evolution of the potential vorticity field associated to the storm (days 1 to 12 ) at pressure level 850 mbar. To simulate the GWS, we introduced on Saturn $₫$ wind flow a vertically extended continuous heat source column with a power of $500 \mathrm{Wm}^{-2}$ and a Gaussian shape with a size of $0.6^{\circ}$. The constant injection of heat from altitude levels 0.5 to 10 bar mimics the continuous latent heat release upward by the convective storm. The model atmosphere depends on the vertical and meridional structure of the zonal wind velocity $U(y, z)$ and the vertical thermal 
structure represented here by the static stability or Brunt-Väisälä frequency $N(P)$, where we use $z$ or pressure $P$ as vertical coordinates and $y$ as meridional coordinate. The wind field structure is modeled as a product of two functions $U(y, p)=u_{h}(y) u_{v}(P)$ where $u_{h}(y)$ is the wind profile at the cloud tops $\left(P_{0}=500\right.$ mbar, ref. 1, 13) and $u_{v}(P)=1+m \ln \left(P / P_{0}\right)$ is a non-dimensional vertical amplitude factor. We tested different values for slope $m$ above and below $P_{0}=500 \mathrm{mbar}^{27-28}$. Similarly, for the thermal structure we adopted $N(P)$ increasing with altitude for $P<500 \mathrm{mbar}^{26}$ and $N(P)=$ constant for $P>500$ mbar. The horizontal domain for the simulations was a $60^{\circ} \times 15^{\circ}$ degree channel with a $0.23^{\circ}$ pix $^{-1}$ resolution and the vertical domain consisted of 8 layers from 10 mbar to 10 bar. The simulation that best resembles the evolution of the observed cloud field was obtained for a low static stability $N^{2}=0.03 \times 10^{-4} \mathrm{~s}^{-2}(P>500$ mbar) and for zonal winds that have slightly positive vertical shear $(m=0.1)$, i. e. winds increasing below cloud tops across the altitude range from $P=0.5$ to 10 bar. 

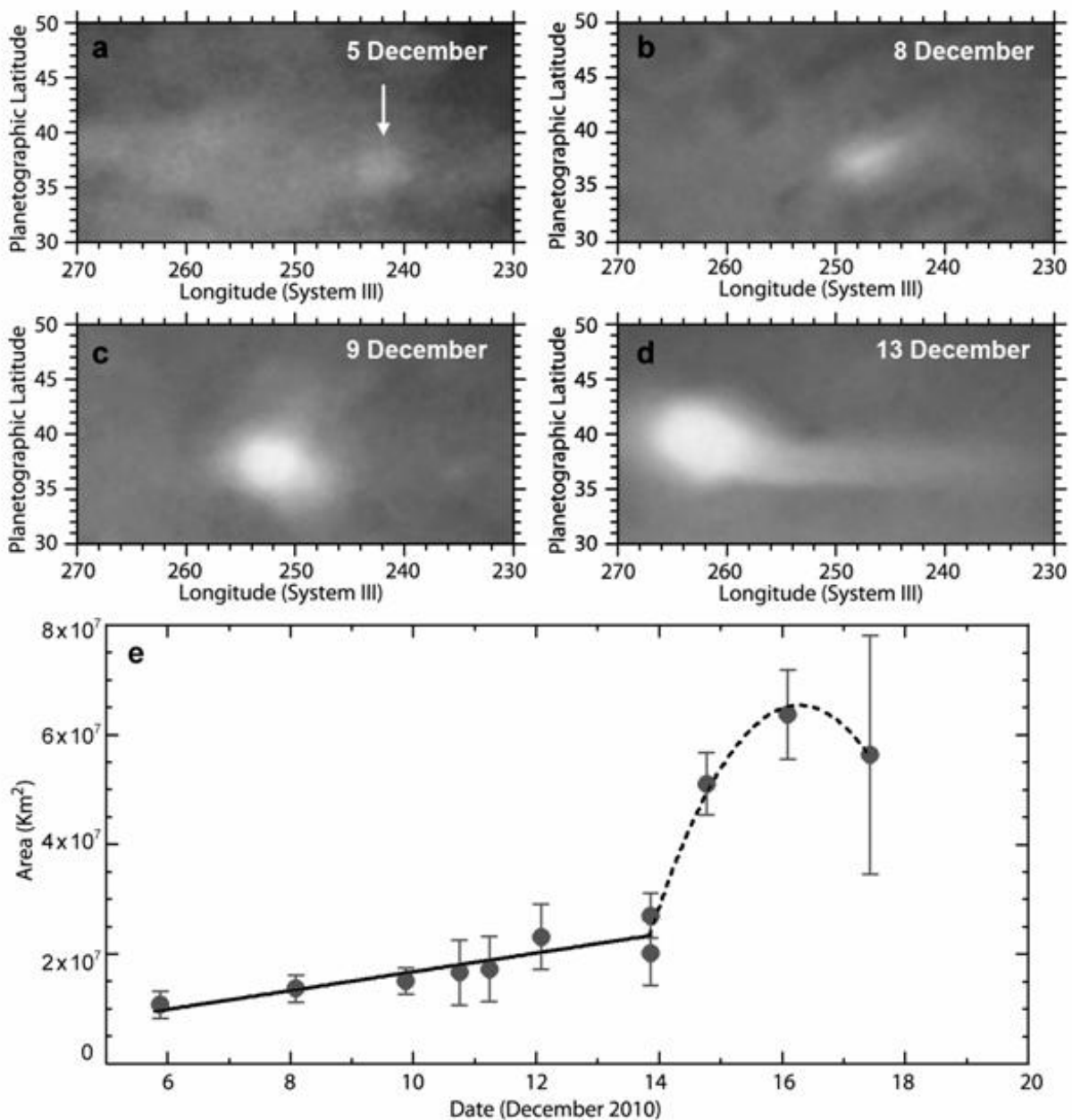

Figure 1 

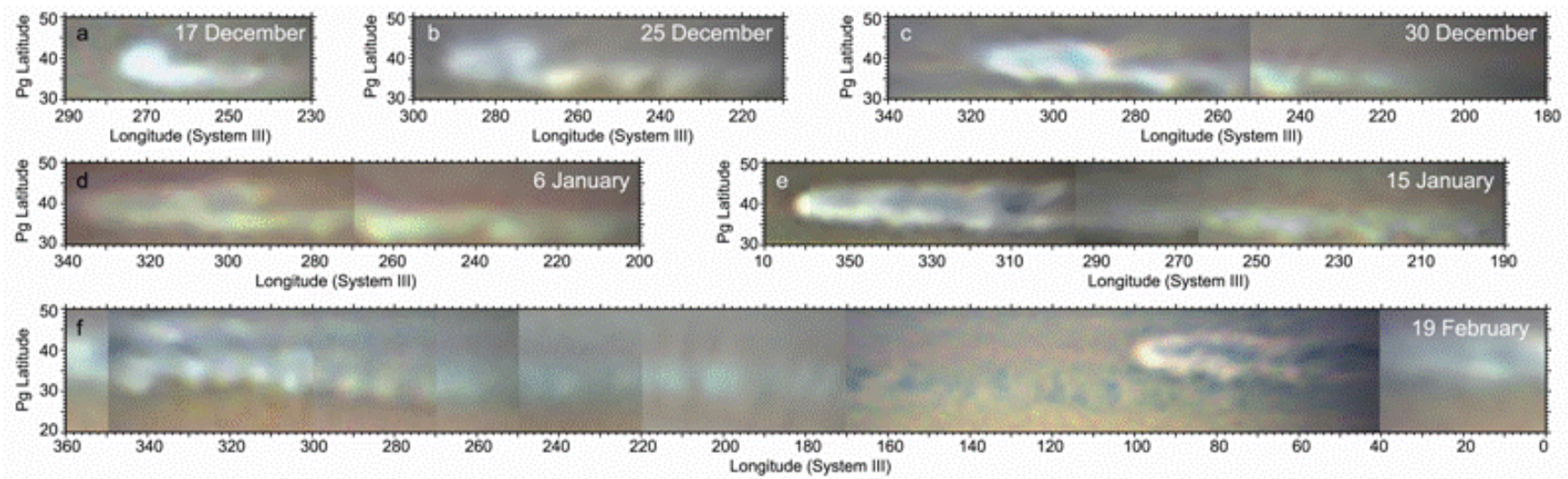

nitude (System III)

Figure 2 


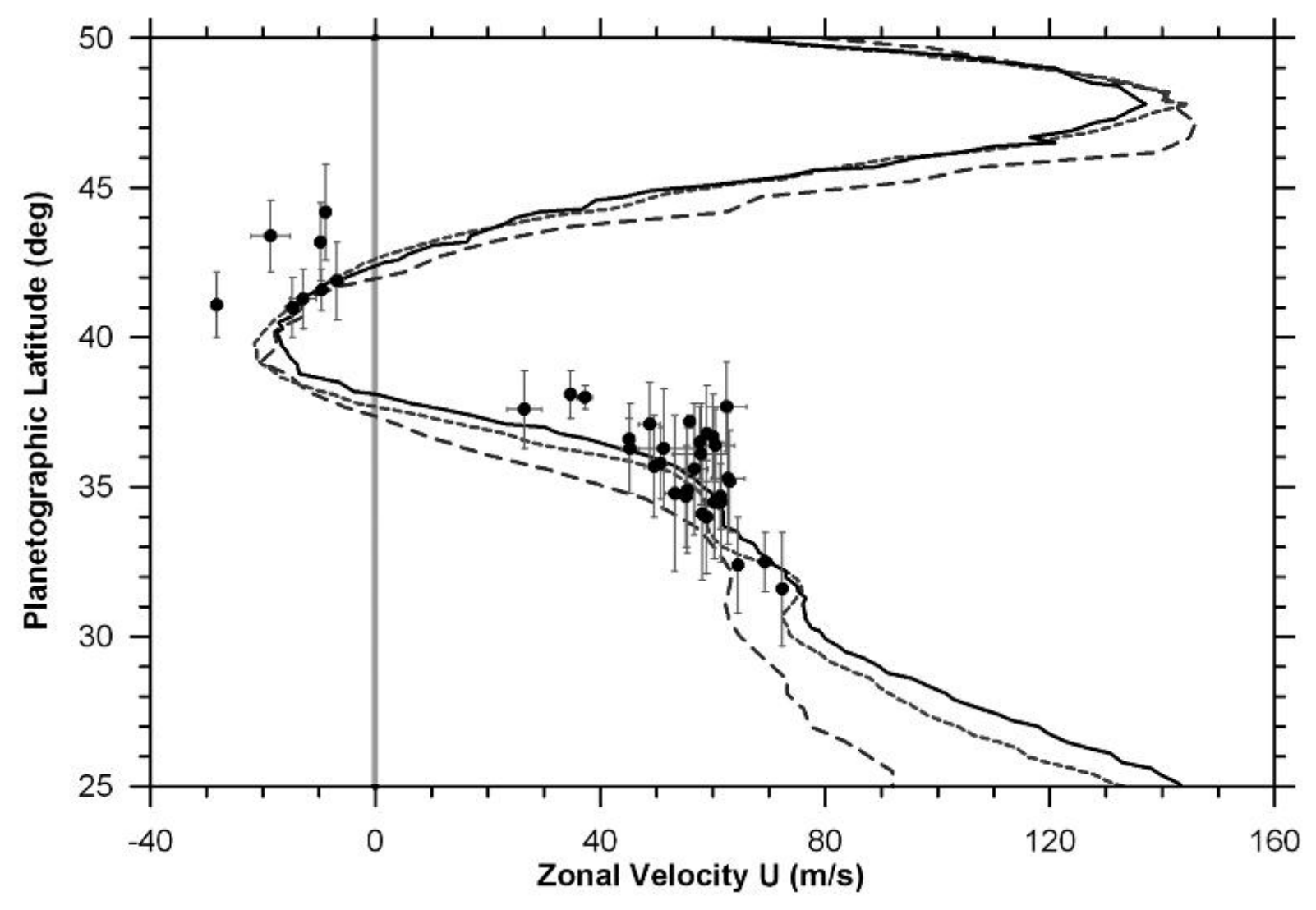

Figure 3 

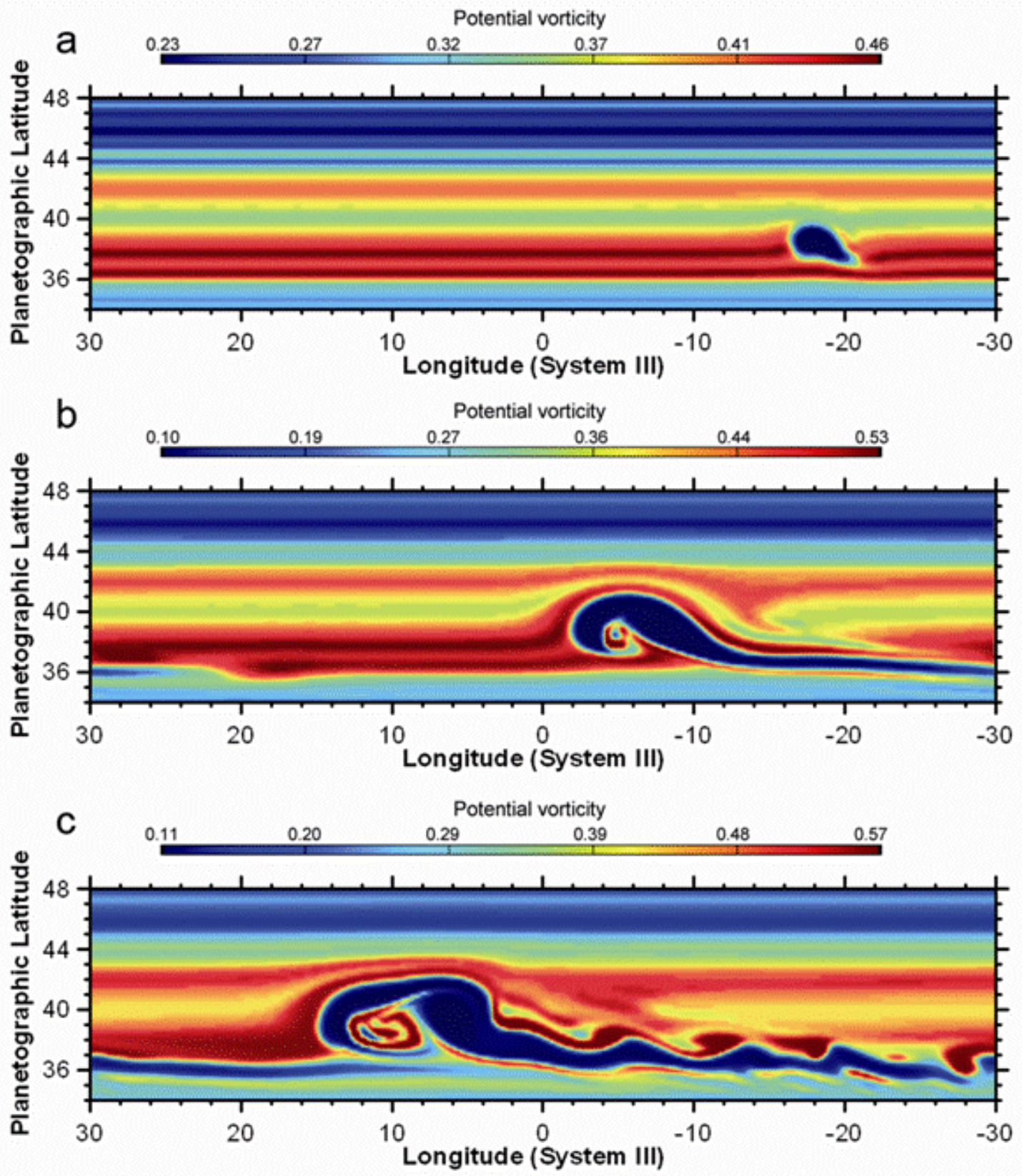

Figure 4 